I construe the sentence it is difficult to treat patients who don't explain their symptoms well; because well is largely superfluous it is fairly irrelevant whether it refers to treat or explain. However, in the following sentence it does rather matter which word is qualified by the final phrase: this case arose through the prescribing of drugs which are habit forming in small quantities, so a change is definitely in order.

Sometimes it is impossible to understand a sentence because a word has two quite different but equally plausible meanings: our previous work has met the criticism . . . . Have we encountered it or have we refuted it? Staying with criticism, if we say that the criticism of Wright is invalid, are we attacking or defending Wright? The possibility that the context may ultimately clarify the position does not excuse the sloppiness of the statement.

Results of calculations are sometimes expressed rather eccentrically: if we are told that the concentration in the treated group was $10 \mathrm{mmol}$; it was half that in the controls, what was the concentration in the controls?
Was it $5 \mathrm{mmol} / \mathrm{l}$ or $20 \mathrm{mmol} / \mathrm{l}$ ? If I have to consult the table of results to find out, then at best the sentence has been wasted.

Not all potential ambiguities are so annoying to readers of articles, and, as I have suggested, some may amuse. If nothing acts faster than Anadin were generally taken at its other face value, perhaps it (either the slogan or the medication) would not have survived as long as it has; ambiguity is probably what makes it (the slogan) successful. Nor can one help liking some misprints which completely change the sense of a sentence. Not perhaps the example which a previous secretary of mine perpetrated by replacing this revised article should now be accepted by this revised article should not be accepted, but what of the dubious assertion that older women are more prone to the risk of pregnancy? Yes, I am amused, but nevertheless the proofreading should have been better. It is remarkably easy not to say what you mean. I hope both my readers and I are agreed about that, and if I have more than two readers I hope the rest agree too.

\title{
Christmas wishes
}

\section{HE Emson}

As I pass yet another birthday, and the end of my working life looms nearer, I begin to think that I should have written this letter years ago. What I ask for, Santa, is hard to stuff in a sack and it may not even be yours to give. As a lifetime writer of articles for medical journals, what I am asking for is a little fairness.

We writers have heard a lot from editors about our sins. We have had our noses rubbed in the dirt about word counts, running titles, spacing, margins, content, and style. We have been told that we can't spell correctly, write grammatically, or think logically. We have left unwritten those things which we ought to have written and we have authored those papers we ought not to have authored, and there is precious little health in us.

Royal University Hospital, Saskatoon, Saskatchewan, Canada S7N 0X0 H E Emson, professor of pathology

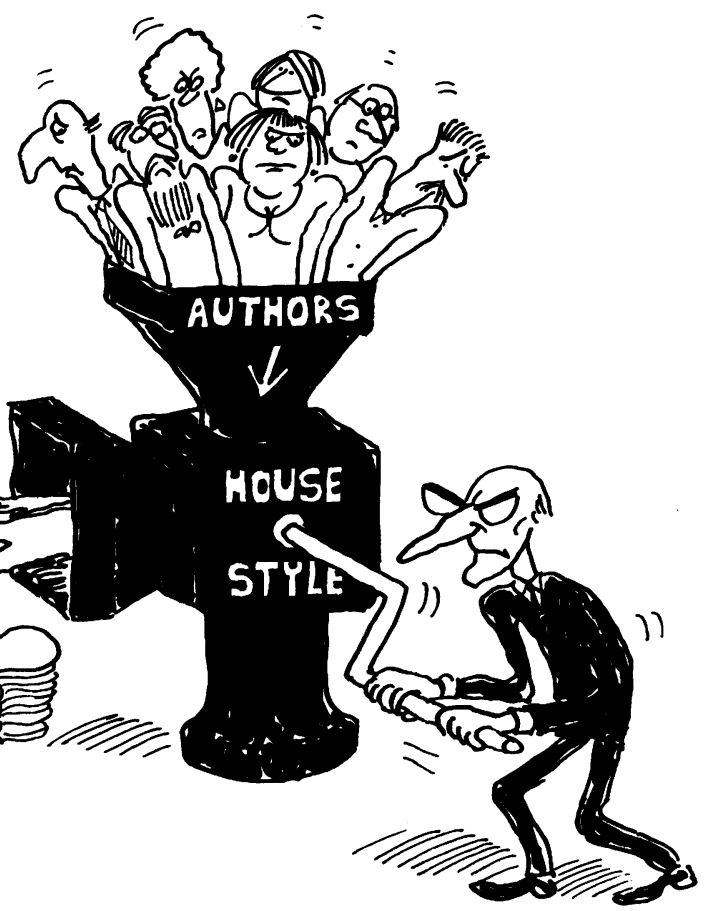

We have taken this lying down because we can't afford to complain: editors hold us in the hollows of their ink stained hands and, short of self publication, we have nowhere else to take our ideas. But even writers turn, in the end.

This outburst, this final breaking of the dam of frustration, has been provoked by the editor of a journal which ranks lower than a caterpillar's ankle on any citation or impact index. The original paper, receipt unacknowledged, took six months to review by no fewer than six reviewers, whose comments and advice were understandably contradictory. A second edition was composed, incorporating as much of the advice as was comprehensible and practical. But when the typescript was returned for the third time it was unrecognisable. It wasn't mine and I withdrew it from the journal's consideration.

\section{Medical Writers' Code of Rights}

This is only one extreme example of how we, the medical writers, are mistreated. Which leads me, dear Santa, to the Medical Writers' Code of Rights.

Firstly, we demand recognition that not all our motives are base. Publish or perish is alive and well, but not the only force that drives us. Some of us think that we really have something worthwhile to say-a study, finding, observation, idea to communicate; to make more people better or fewer people worse, to stimulate thought, to provoke reaction.

Secondly, we need clear and concise directions as to what you editors want, printed frequently in your journals. The more prestigious the publication, the more clear and user friendly are its instructions to authors-apart from those which give none at all, forcing you to telephone and inquire if unsolicited submissions are considered.

When we have confided our latest baby to you we expect prompt acknowledgment and an indication as to whether it has been accepted with jubilation, rejected out of hand, or is under consideration. This should come by mail or fax and give your reference number or other identifier and an estimated date by which a decision will be made. 
Please choose your reviewers carefully and keep them few. Try to ensure that they have some elementary knowledge of the subjects they review and have no known animosity towards the author. A good article in a small discipline will almost inevitably bear the imprint of its writer, however anonymised. What you should want is individuality. You don't want every paper to sit blandly in the middle, at the peak of the distribution curve, stimulating, provoking, and offending nobody. Demand from your reviewers the same promptitude and courtesy as they hope to receive-if they cannot reply within, say, four weeks they should say so. They should be broadminded and honest enough to recognise that ideas which they do not share may be worth stating.

\section{House style: the chilly spirit}

Reviewers do not have to quibble for the sake of itand the same goes for you when it comes to editing. There is a chilly spirit that hovers in editorial offices, like the ghost of Christmas never to come, and is called house style-the desire to reduce everything to the attractiveness of cold rice pudding on a white plate. I have visions of ranks of assistant editors, wizened creatures clad in grey, at dusty desks in a huge, dim room, emasculating my efforts. I think that by now I know how to write, what I want to say, and how to say it, usually without transgressing common decency or the laws of libel. I have confidence in content and pride in style. Why must you mess them about?

It is nice to have some estimate about the date of publication. When you send proofs for editing, try to give a reasonable time for response. I am not always in the office, or even in town, and I do have commitments to others. Don't ask for a reply by telephone or leave me to find out that you leave your office, two time zones to the east, at noon on Fridays.

\section{Good work well done}

Generally, editorial action varies with the prestige of the journal-and I have managed to get to the top, occasionally. Those at the peak accept, reject, or review quickly. They acknowledge promptly and assign a file number. Their reviewers are few, quick, knowledgeable, sensible, and brief. Editorial tampering with text is minimal or nil and may be withdrawn after expostulation and explanation. A publication date is assigned. Printers are literate and proofs reasonable. Staff in the editorial office are competent in at least one official language when contacted by telephone.

So, dear Santa, if you can reach editors, legions of frustrated writers will sing your praises. Wrap this round a lump of coal in the stockings of the bad guys; stick it to the sugar plums for the goodies.

Hope springs eternal, and I remain, yours in gratitude.

\section{An audit of excuses}

VWright

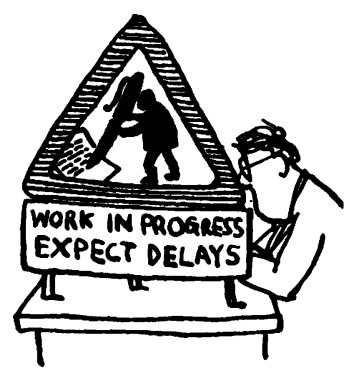

The Rheumatology and Rehabilitation Research Unit at the University of Leeds is a vigorous, productive department in four segments, clinical science, bioengineering, clinical pharmacology, and rehabilitation. To foster the illusion of having things under control, the professor has a monthly research meeting at 730 am and also a quarterly review of each group. The normal agenda comprises apologies for absence (none if members value a reference for their next job), suggestions for communications to the next meeting of the British Society of Rheumatology or the British Orthopaedic Research Society, progress reports of papers to be published, review of work being currently undertaken, and ideas for future studies. At the last meeting of the clinical review group there were 80 papers in various stages of preparation. As it was the professor's last meeting before retirement, under "any other business" he was presented with a list of "reasons," culled over the years, for the lack of progress of papers. In the expectation that they will be of value to other junior staff members in a similar position they are reproduced here.

\section{Writing up}

These excuse the non-appearance of the results of work, often long since finished, which has not seen the light of day.

- It's in the pipeline

- It's next on the list

- It's on the pending pile

- It's at the top of the pending file

- It's at the bottom of the pending file (with the variation, It got buried at the bottom of my briefcase)

- I'm waiting for another trip on the Orient Express
- I'll do it when I have finished the thesis/chapter/ book

- I'll have more time in my next post (a comment likely to perforate the professor's ulcer since he has seldom known anyone do this, however honourable their intentions)

- It's with the secretaries (not surprisingly it has failed to materialise since it was given to them only yesterday)

- Oh look, the tea has arrived! (this is known as being saved by the tea bell)

\section{Almost writing up}

- I'm collecting more data (this task seems infinitely more preferable to writing and often results from a failure to appreciate that good research always poses more problems that it answers, so it will never be complete)

- I'm re-analysing the data/doing some more statistics to make it credible (this lugubrious comment usually means the study should never have been started in the first place, or at least not without consulting a statistician)

- Unfortunately the data are on an IBM incompatible computer

- I cannot find the right statistical test to prove it worked (despite the sizeable fee we paid to the statistics department)

- It's a multicentre study, so it is the responsibility of the University of Grantchester-or worse still, a pharmaceutical company that is most unlikely to put pen to paper to describe the results of a study which showed their products to be marginally worse than placebo

- I'm starting again in view of recent work 